\title{
Robotic surgery for colorectal disease: review of current port placement and future perspectives
}

\author{
Jong Lyul Lee, Hassan A. Alsaleem, Jin Cheon Kim \\ Department of Surgery, Asan Medical Center, University of UIsan College of Medicine, Seoul, Korea
}

Purpose: As robotic surgery is increasingly performed in patients with colorectal diseases, understanding proper port placement for robotic colorectal surgery is necessary. This review summarizes current port placement during robotic surgery for colorectal diseases and provides future perspective on port placements.

Methods: PubMed were searched from January 2009 to December 2018 using a combination of the search terms "robotic" [MeSH], "colon" [MeSH], "rectum" [MeSH], "colorectal" [MeSH], and "colorectal surgery" [MeSH]. Studies related to port placement were identified and included in the current study if they used the da Vinci S, Si, or Xi robotic system and if they described port placement.

Results: This review included 77 studies including a total of 3,145 operations. Fifty studies described port placement for left-sided and mesorectal excision; 17, 3, and 7 studies assessed port placement for right-sided colectomy, rectopexy, transanal surgery, respectively; and one study assessed surgery with reduced port placement. Recent literatures show that the single-docking technique included mobilization of the second and third robotic arms for the different parts without movement of patient cart and similar to previous dual or triple-docking technique. Besides, use of the da Vinci Xi system allowed a more simplified port configuration.

Conclusion: Robot-assisted colorectal surgery can be efficiently achieved with successful port placement without movement of patient cart dependent on the type of surgery and the robotic system.

[Ann Surg Treat Res 2020;98(1):31-43]

Key Words: Colon, Rectum, Robotics, Robotic surgical procedure, Surgery

\section{INTRODUCTION}

Robotic colorectal surgery was first performed in 2002, with studies describing robot-assisted laparoscopic colorectal surgery using the AESOP system (Computer Motion Inc., Goleta, CA, USA) for camera control and 2 patients who underwent da Vinci robot-assisted colonic mobilization [1,2]. Types of colorectal surgery performed robotically have included colectomy, total mesorectal excision (TME), perineal resection, total colectomy and rectopexy, with robotic colorectal surgery performed in patients with various disease, both benign and malignant [3-5]. Although several types of robotic systems were utilized previously, including the robotic Puma 560, PROBOT, ROBODOC, AESOP, DaVinci Robot, and Zeus systems [6], the da Vinci surgical system (Intuitive Surgical, Inc., Sunnyvale, CA, USA) currently predominate.

Compared with laparoscopic instruments, the da Vinci surgical system provides 3-dimensional imaging, excellent ergonomics, and tremor or motion scaling [7]. Robotic arms have enabled solo laparoscopic surgery, eliminating the need for an assistant, providing greater stability of views and reducing surgeon fatigue [8]. However, it is not presently confirmative
Received August 13, 2019, Revised October 28, 2019,

Accepted November 5, 2019

\section{Corresponding Author: Jin Cheon Kim}

Department of Surgery, Asan Medical Center, University of Ulsan College of Medicine, 88 Olympic-ro 43-gil, Songpa-gu, Seoul 05505, Korea

Tel: +82-2-3010-3489, Fax: +82-2-474-9027

E-mail: jckim@amc.seoul.kr

ORCID: https://orcid.org/0000-0003-4823-8619
Copyright (c) 2020, the Korean Surgical Society

(c) Annals of Surgical Treatment and Research is an Open Access Journal. All articles are distributed under the terms of the Creative Commons Attribution NonCommercial License (http://creativecommons.org/licenses/by-nc/4.0/) which permits unrestricted non-commercial use, distribution, and reproduction in any medium, provided the original work is properly cited. 
whether these theoretical benefits of robotic colorectal surgery translate into favorable patient outcomes. Registered randomized clinical trials, including the international robotic versus laparoscopic resection for rectal cancer trial (NCT01196000) and the South Korean trial to assess robotassisted surgery and laparoscopy-assisted surgery in patients with middle or lower rectal cancer (NCT01423214), are currently comparing laparoscopic and robotic surgery in patients with rectal cancer. Early results of the international robotic versus laparoscopic resection for rectal cancer trial (NCT01196000) have reported a lower conversion rate to open surgery for robotic than for laparoscopic surgery in male and obese patients [9].

Robotic surgery, however, has several drawbacks, including the lack of haptic sense, high cost, a bulky robotic cart, and collision between robotic arms [10]. Although the learning curve appears to be shorter for robotic than for laparoscopic colorectal surgery $[10,11]$, understanding proper port placement for robotic colorectal surgery is necessary. Although the manufacturer of the da Vinci system recommends different pattern of port placements for right abdominal, left abdominal and pelvic surgery, they need to be modified according to diverse surgical approaches.

This systematic review evaluated and analyzed current patterns of port placement for robotic surgery in patients with colorectal diseases, as well as providing future perspectives on port placement.

\section{METHODS}

PubMed were searched from January 2009 to December 2018 using a combination of the search terms "robotic" [MeSH], "colon" [MeSH], "rectum" [MeSH], "colorectal" [MeSH], and "colorectal surgery" [MeSH]. Relevant studies were identified, and their reference lists were searched manually for additional relevant publications. Case series, retrospective and prospective studies, and randomized controlled trials with appropriate data were included if they used the da Vinci S, Si, or Xi robotic system and if they described port placement. Case reports, video vignettes, letters, editorials, review articles, articles describing robotic technologies, animal experiments, studies describing education about or simulation of robotic methods, studies with inappropriate data, non-English literatures, and studies that did not appropriately explain exactly about port placement were excluded (Fig. 1). Publications using the New Senhance Telerobotic and Soloassist systems were also excluded.

Data from the same type of operation performed during the same period at the same institution were considered duplicates, whether or not the corresponding authors were the same. If studies were identified as duplicates, only the study with the largest group of patients, the most parameters reported, or the most recent data was included.

Data collected from all included studies consisted of year of publication, first author, journal, robotic platform, operation type, number of ports, number of docks, docking time, total operation time, and number and rate of conversion. Variables were analyzed separately according to type of operation, including right-sided colectomy, left-sided colectomy, mesorectal excision, rectopexy, transanal approach, and surgery using a single-site platform.

\section{RESULTS}

\section{Literature search}

The literature search initially yielded 785 titles, with 560 remaining when only those dealing with actual robotic colorectal surgery were included. After excluding the reviews and meta-analyses $(n=109)$, editorials and letters $(n=77)$, video vignettes $(n=56)$, non-English language articles $(n=38)$, training programs $(n=37)$, case reports $(n=27)$, and studies using robotic systems other than the da Vinci system $(n=8)$, 208 studies were included. Of these, 131 studies were excluded, 108 articles that did not describe port placement and 23

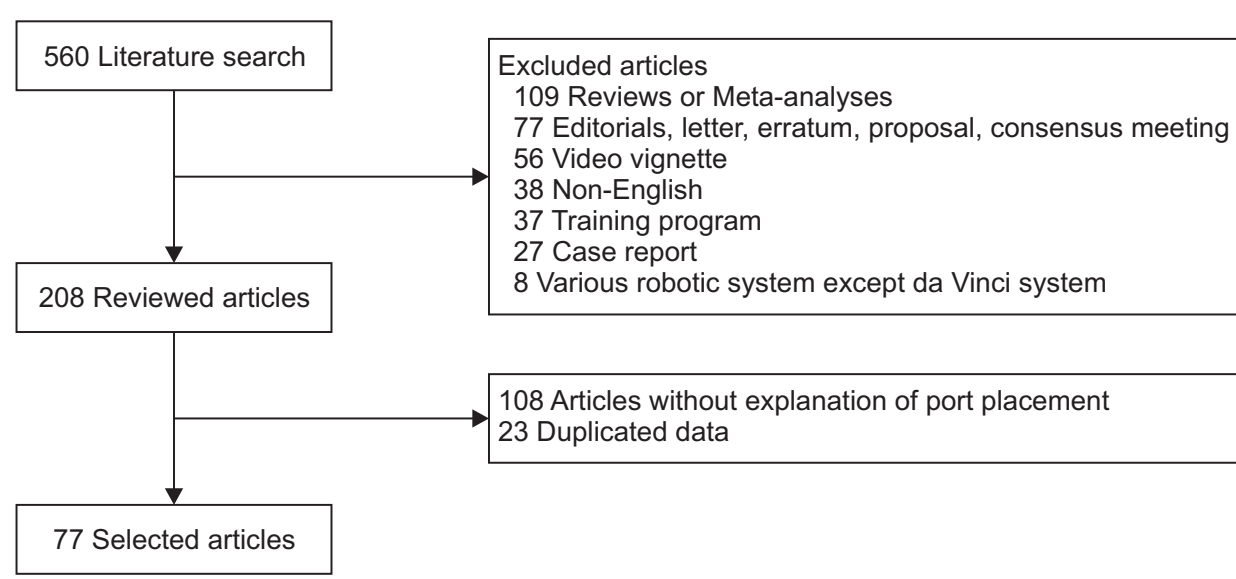

Fig. 1. A diagram of literature search and selection. 


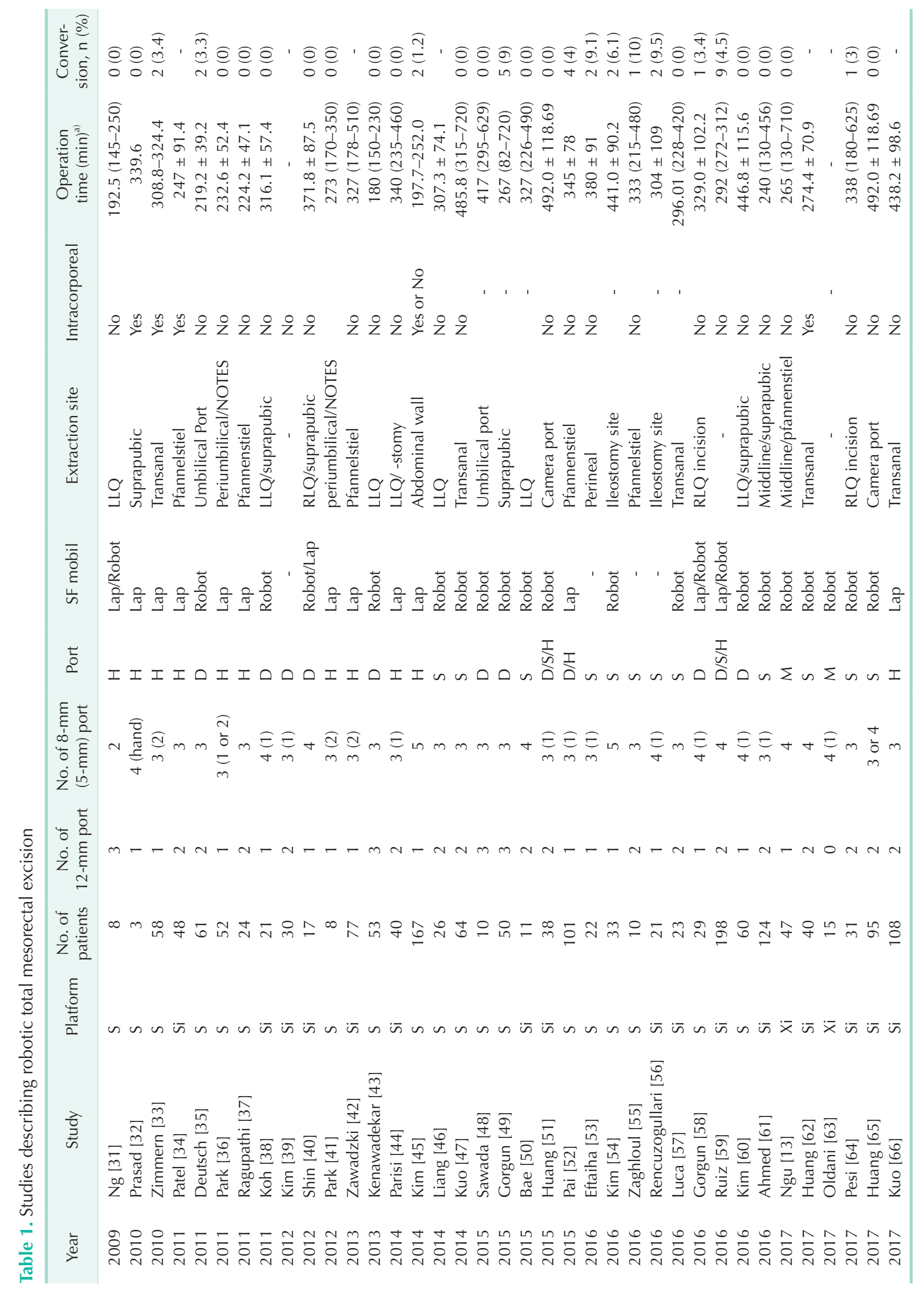




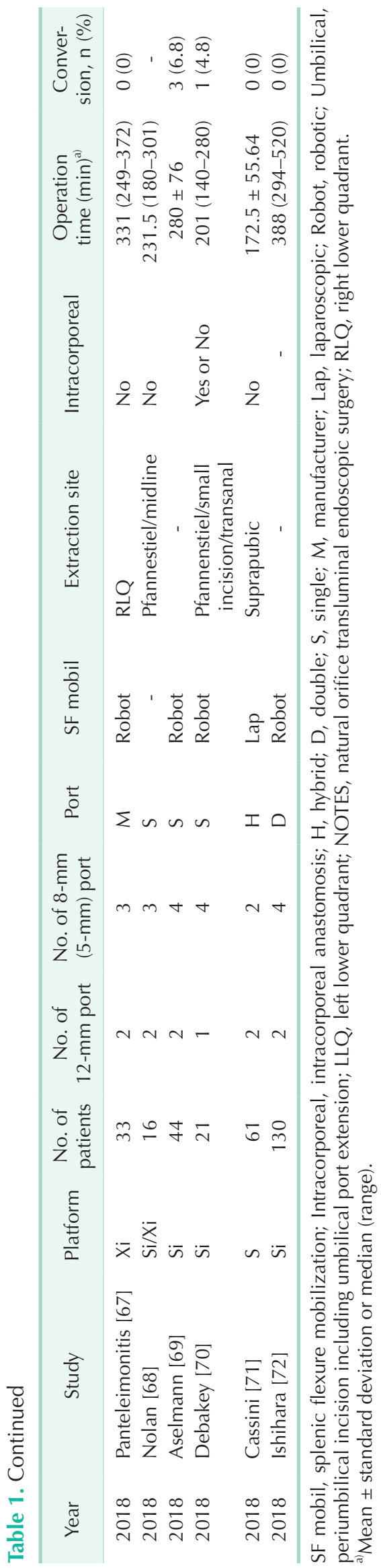

duplicated data. Thus, 77 studies were systematically reviewed (Fig. 1).

\section{Characteristics}

The number of publications that include robotic colorectal surgery has been constantly increasing over time, from 16 titles in 2009 to 183 titles in 2018 among the total of 785 titles. The 77 included studies described a total of 3,145 operations. Forty-three studies included 2,425 patients who underwent mesorectal excision, including anterior, low anterior, intersphincteric, and abdominoperineal resection, and Hartmann's procedure. Sixteen studies included 468 patients who underwent right-sided colectomy, 6 studies described 155 patients who underwent left-sided colectomy, 4 studies included 90 patients who underwent mesh ventral rectopexy, 7 studies described 113 patients who underwent transanal surgery, 2 studies included 19 patients who underwent total colectomy or total proctocolectomy, 1 study included patients who underwent transverse colectomy, and 1 study described patients who underwent surgery using a single-site platform. The robotic platforms included the da Vinci S or Si system for 2,920 operations and the da Vinci Xi system for 225 operations.

\section{Port placement for TME and left-sided colectomy}

Although the da Vinci system has been used for colorectal surgery, more than $70 \%$ of these operations were robotic TME. Although no technique has become standardized for left colon dissection and low anterior resection, several procedures have been described for the da Vinci S and Si systems (Table 1). The hybrid approach, in which various types of ports are placed using laparoscopic approach, consisted of laparoscopic mobilization of the splenic flexure and left colon, followed by robotic docking for dissection of the pelvis and completion of the procedure (Fig. 2A). The double- or triple-docking technique included docking from the left upper or left hemi-abdomen for dissection of the splenic flexure, followed by docking to the left lower abdomen and placing an extra-port on the right side (Fig. 2B). The single-docking technique included mobilization of the second and third robotic arms for the different parts without movement of patient cart (Fig. 2C) [12].

Use of the da Vinci Xi system allowed a more simplified port configuration, with most studies using the configuration recommended by the manufacturer with minor variations (Fig. 2D). Basically, the left-sided colectomy incorporated mobilization of the splenic flexure. Four studies using the da Vinci S or Si system described the double docking or hybrid technique as port placement, and 2 studies involving the da Vinci Xi system used the procedure described by the manufacturer, along with instruction and universal port placement (Table 2). 


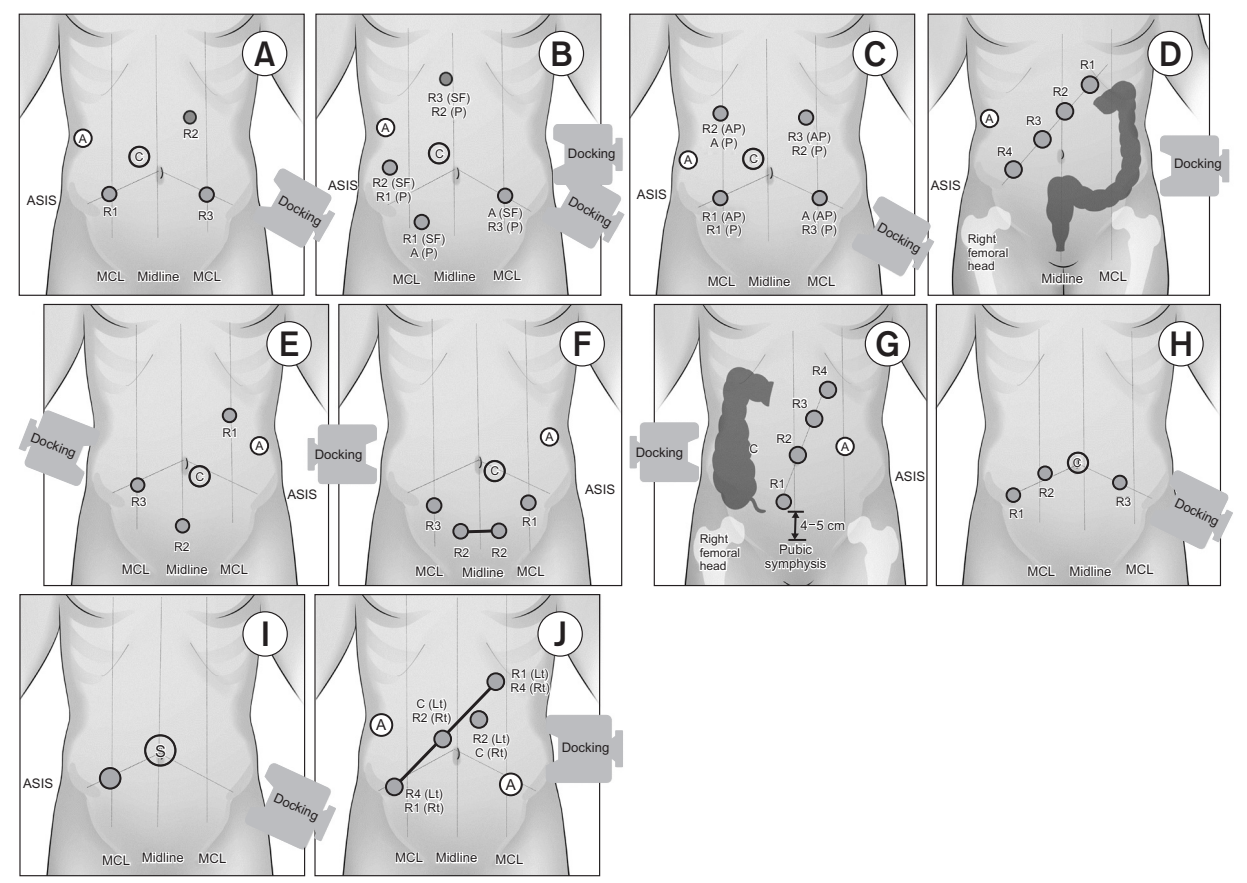

Fig. 2. Port placement for robotic total mesorectal excision (A-D) or left-sided colectomy (A, B) using the da Vinci S, Si, or Xi system. (A) Port placement for hybrid technique including laparoscopic splenic flexure or left colon mobilization. (B) Double docking port placement with movement of the patient cart according to the dissection area. (C) Single-docking port placement including the rotation of robotic arms without movement of patient cart. (D) Port placement recommended by the manufacturer using the da Vinci Xi system. Port placement for robotic right-sided colectomy (E-G) and ventral mesh rectopexy $(\mathrm{H})$. (E) Reversed-L-shaped port placement with minor variation using the da Vinci S or Si system. (F) Suprapubic port placement with wound extension between the 2 suprapubic ports for the extraction of the specimen. (G) Port placement that was recommended by the manufacturer using the da Vinci Xi system. $(\mathrm{H})$ Port placement with minor variations for robotic ventral mesh rectopexy that was focused on the pelvic dissection. Extraordinary port placement. (I) Reduced port placement for anterior resection using single-site platform with an additional port. (J) Universal port placement for all 4-quadrant colorectal surgery. R1, arm 1 for monopolar scissors or cautery hook; R2, arm 2 for Maryland or Fenestrated bipolar forceps; R3, arm 3 for tip-up fenestrated grasper or Cadiere forceps; A, assistant port; C, camera port; ASIS, anterior superior iliac supine; MCL, mid-clavicular line; SF, dissection for splenic flexure; P, dissection for pelvis; Docking, placement of the patient cart; S, singlesite platform.

\section{Port placement for right-sided colectomy}

Port placement of the da Vinci S or Si system for rightsided colectomy usually consisted of the reversed-"L"-shaped procedure, except 4 studies that used left lateral or verticallystraight port placement (Table 3, Fig. 2E). The da Vinci Xi system used the procedure described by the suprapubic port placement and manufacturer's recommendation (Fig. 2F, G). All rightsided colectomies were performed using the single-docking technique.

\section{Port placement for mesh ventral rectopexy}

Complete rectal prolapse was treated by mesh ventral rectopexy using the da Vinci S or Si system. All 4 studies reported transverse port placement with the single-docking technique (Table 4, Fig. 2H).

\section{Port placement for transanal approach and reduced port placement}

The transanal approach using a robotic system included robotic transanal minimally invasive surgery (TAMIS) and transanal total mesorectal excision (TATME). Four studies reported robotic TAMIS, and 3 reported robotic TATME. Robotic TAMIS was usually performed using 3 robotic arms due to limitations of the transanal space, whereas, robotic TATME used all 4 robotic arms due to abdominal phase (Table 5). One study described port placement for reduced port anterior resection using the robotic single-site platform with an additional 12-mm port (Fig. 2I).

\section{DISCUSSION}

Robotic surgery is a major advance in colorectal surgery and is increasingly utilized for colorectal resection, irrespective of tumor locations [3]. However, beginning colorectal surgeons hesitate to perform robotic surgery because of its various drawbacks including the need for proper port placement, the absence of tactile sensations, and high cost. This review summarizes current pattern of port placement for colorectal surgery and 


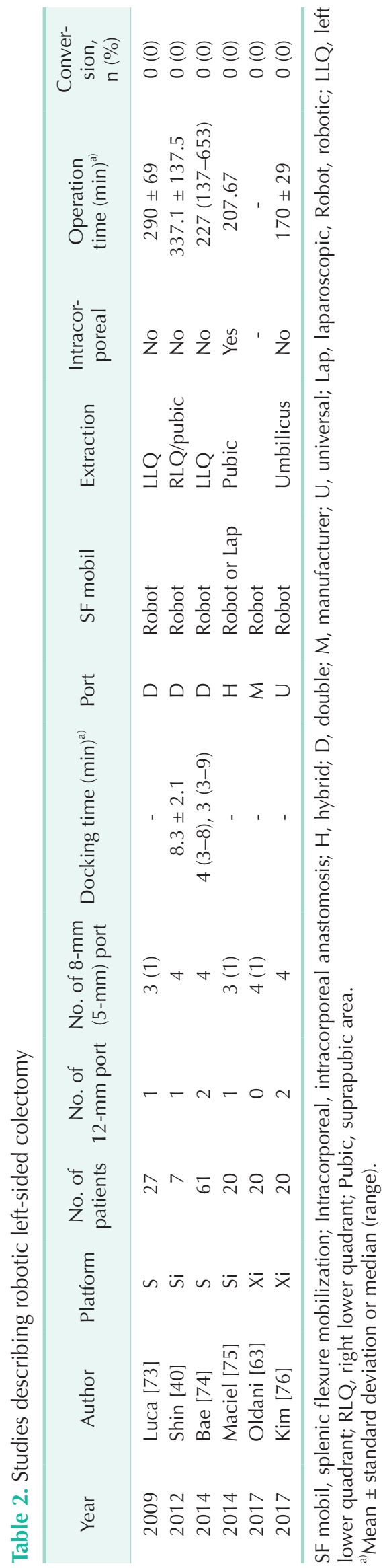

provides information to easily overcome problems related to port placement during various types of robotic colorectal surgery.

Earlier published studies described the collision-related difficulties encountered during docking and port placement, especially when surgeons attempted to operate across other abdominal quadrants [13]. Reflecting the learning curve inherent to the adoption of robotic colorectal surgery, the use of standardized techniques and increased experience have resulted a shortening of port placement and docking time [11,1416]. The present review described the simplified port placement associated with the da Vinci system and type of operative, findings that may be helpful for those learning robotic colorectal surgery. Improvements in the da Vinci system require robotic surgeons to review previous as well as recent studies.

Port placement for earlier da Vinci models, including the 3 arm-based S to Si system, generally involved scattered sites across the abdomen [17]. The Xi model, however, allows a more simplified port configuration and a reduced learning curve, resulting in shorter docking times [13]. Studies about TME or left-sided colectomy that were published during the early 2010s, reported more frequent use of hybrid techniques and increases in the number of ports. The hybrid approach and double docking technique allowed to overcome the limited range of motion of the robotic arm during splenic mobilization and pelvic dissection, however, those techniques had longer operation time, compared with the single-docking technique $[18,19]$. The single-docking technique provides advantages in omitting the movement of the patient cart, resulting in shorter operative time, whereas, that technique might need to overcome the learning curve and to understand the port configuration and the proper distance between the ports [18]. Although the da Vinci S and Si systems are being replaced by the da Vinci Xi system, studies describing port placement have decreased over time, making port placement slightly problematic when using the Xi platform. Although the console experience and operative technique of the Xi system similar to those of the S and Si systems, the extra features of the Xi system, including collision avoidance mechanisms, automatic targeting, motion-censored table, and boom features, appear to reduce the stress associated with port placement $[13,20]$.

The reversed-"L"-shaped port placement for robotic right colectomy was used in almost all studies using the $\mathrm{S}$ or $\mathrm{Si}$ system, except that 22 studies published in 2010 involved diamond-shaped or vertically-straight port placement using the 3 arm-based S system and 2 studies with left lateral port placement. The reversed-"L"-shaped port placement for the S or Si system results in wider coverage of the right upper quadrant than diamond-shaped or left lateral port placement. A recent study described use of a suprapubic approach, with extension of the incision between the ports and the extra features of the 
Jong Lyul Lee, et al: Port placement for robotic colorectal surgery

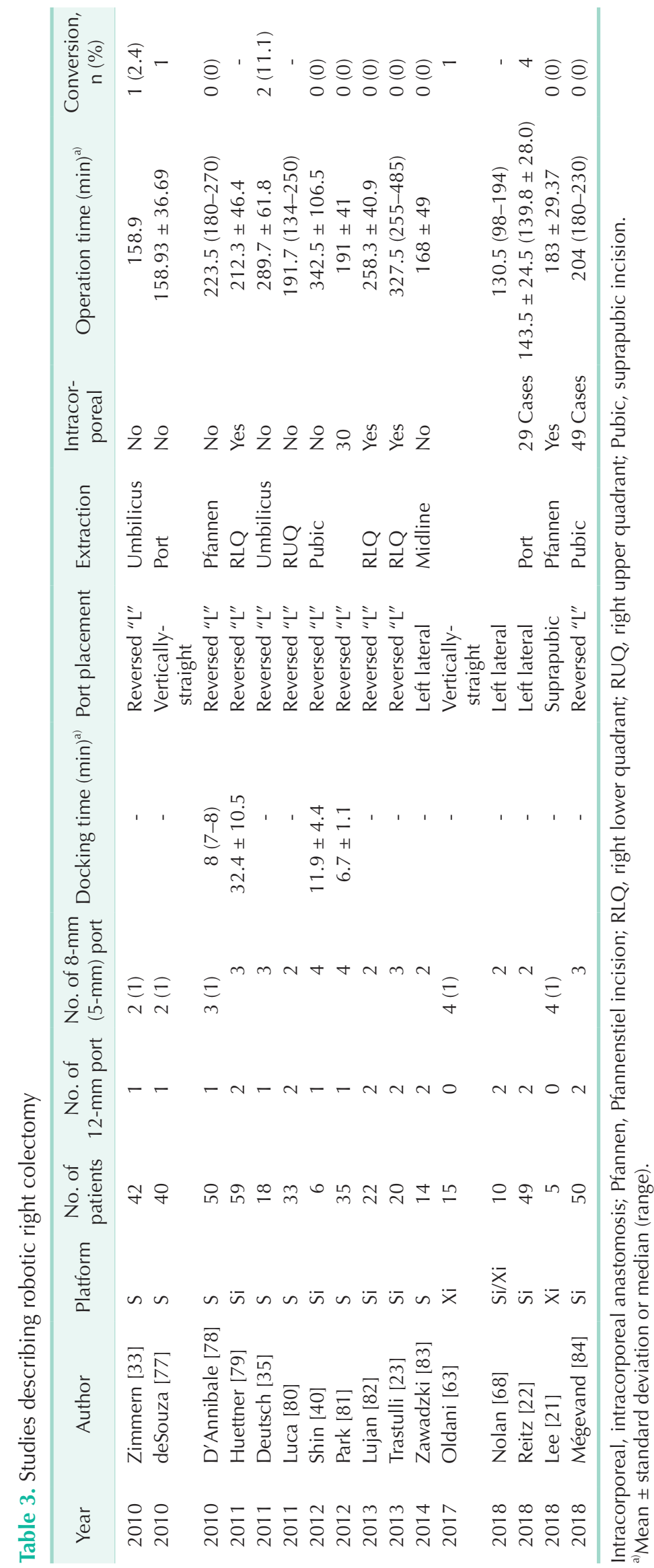



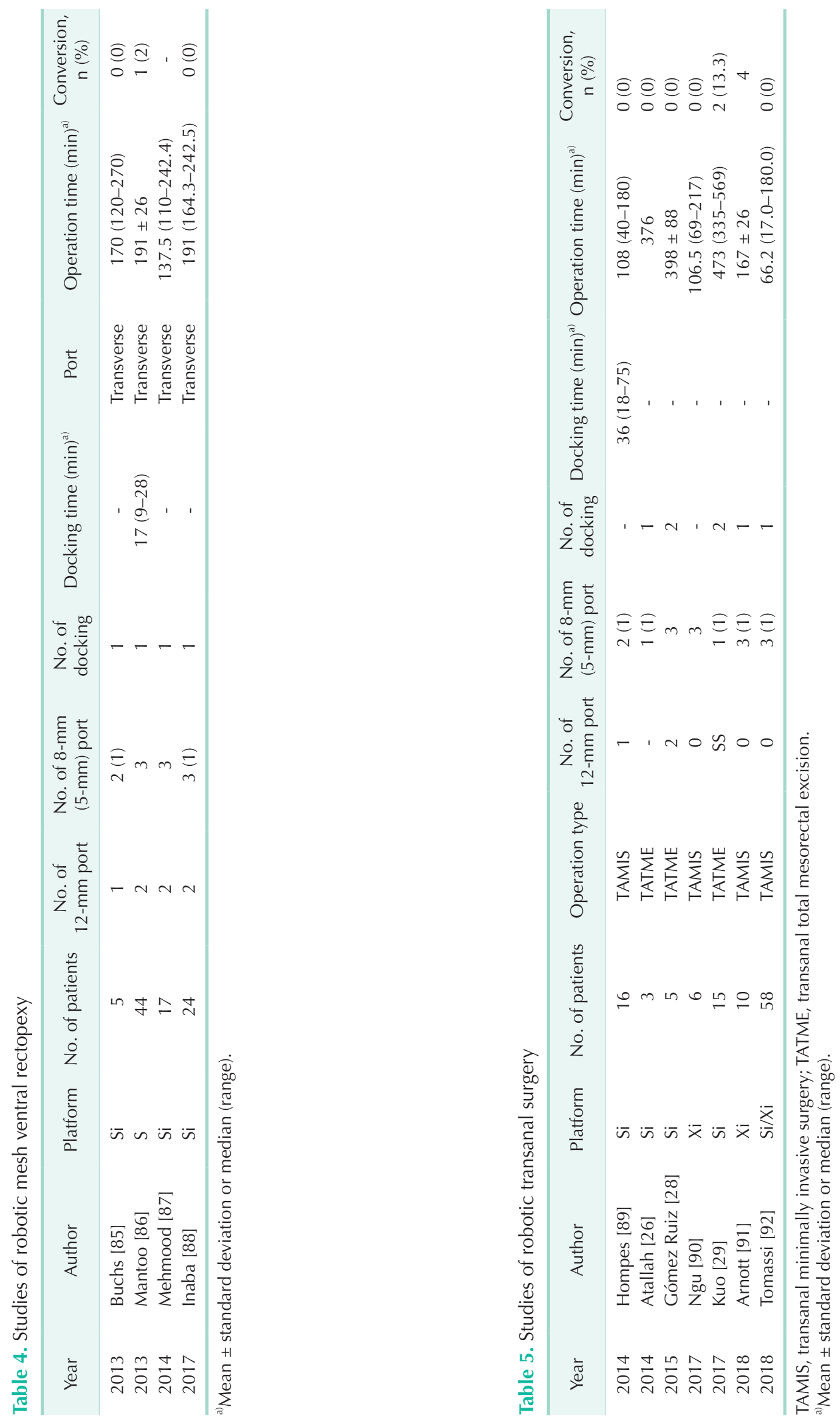
$\mathrm{Xi}$ system providing a more cosmetic effect, and the longer arm and boom system resulting in wider and more flexible coverage than previous platforms [21]. Many of the reviewed studies described intracorporeal anastomosis during robotic right colectomy, with a rate of adoption higher than that of robotic TME. Although this intracorporeal technique required a longer operation time, it maximized the outcomes of robotic right colectomy, including better cosmetic results and easier suturing, compared with a laparoscopic approach, resulting in a completely minimally invasive procedure [22-24].

Although the innovative transanal and transrectal techniques have been developed in recent years, the present review included only 7 studies describing port placement using these robotic methods. A pure TATME procedure for rectal cancer remains technically challenging, with almost $40 \%$ of patients requiring abdominal assistance [25]. Abdominal assistances also remained essential when robotic systems were utilized to overcome the limitations of the TATME [26-29]. The robotic abdominal approach requires appropriate port placement, whereas the optimal docking angle is required for the robotic transanal approach. One study suggested that the optimal docking angle for the robotic cart to avoid external collisions was an oblique approach from the left of the patient, at a $45^{\circ}$ angle to the operating table [29]. The port configuration of the transanal area usually included 2 operative trocars at the base and a trocar for the $30^{\circ}$ upward-looking endoscope at the apex [29], and the port placement sometimes changed 2 operative trocars in the apex according to the tumor location during TAMIS. The da Vinci SP model, which recently became available, may be more efficient in the transanal approach. Further experiences are needed to assess the outcomes of TATME using the SP model.

Apart from the ordinary robotic procedures, the reduced port placement with the intracorporeal anastomosis would allow it to maximize the cosmetic effect even this study included only 1 study. This reduced port placement with a sing-site platform or the SP model may have the possibility of an advance. Port placement using the Xi system may be optimal for singlestage totally robotic dissection of the entire abdomen [30], Universal port placement maximally utilized the advantages of the da Vinci Xi model, including the universal 8-mm da Vinci port that allowed insertion of the endoscope into any port, a rotatable boom that could cover all 4 quadrants of the abdomen, without any instrumental collisions (Fig. 2J) [30]. Universal port placement may be required for proper placement of the assistant port and for determining the axis of the linear port line.

In conclusion, recent studies show that the operation time and conversion rate of single-docking technique in the da Vinci Si system are similar to previous dual or triple-docking technique and use of da Vinci Xi system allows a more simplified linear port configuration. Although port placement using the robotic system varies by operation type and surgeon preference, development of port placement would allow to reduce the number of port and movement of cart and to realize more minimally invasive surgery.

\section{CONFLICTS OF INTEREST}

No potential conflict of interest relevant to this article was reported.

\section{ACKNOWLEDGEMENTS}

This work was supported by National Research Foundation (KRF) grant funded by the Korean Government, Ministry of Science and ICT (2016R1E1A1A02919844).

\section{REFERENCES}

1. Merola S, Weber P, Wasielewski A, Ballantyne GH. Comparison of laparoscopic colectomy with and without the aid of a robotic camera holder. Surg Laparosc Endosc Percutan Tech 2002;12:46-51.

2. Weber PA, Merola S, Wasielewski A, Ballantyne GH. Telerobotic-assisted laparoscopic right and sigmoid colectomies for benign disease. Dis Colon Rectum 2002;45:1689-94.

3. Biffi R, Luca F, Bianchi PP, Cenciarelli S,
Petz W, Monsellato I, et al. Dealing with robot-assisted surgery for rectal cancer: current status and perspectives. World J Gastroenterol 2016;22:546-56.

4. Isik O, Gorgun E. How has the robot contributed to colon cancer surgery? Clin Colon Rectal Surg 2015;28:220-7.

5. Heemskerk J, de Hoog DE, van Gemert WG, Baeten CG, Greve JW, Bouvy ND. Robot-assisted vs. conventional laparoscopic rectopexy for rectal prolapse: a comparative study on costs and time. Dis Colon Rectum 2007:50:1825-30.

6. Tebala GD. History of colorectal surgery: a comprehensive historical review from the ancient Egyptians to the surgical robot. Int J Colorectal Dis 2015;30:723-48.

7. Melich G, Pai A, Shoela R, Kochar K, Patel S, Park J, et al. Rectal dissection simulator for da vinci surgery: details of simulator manufacturing with evidence of construct, face, and content validity. 
Dis Colon Rectum 2018;61:514-9.

8. Makin GB, Breen DJ, Monson JR. The impact of new technology on surgery for colorectal cancer. World J Gastroenterol 2001;7:612-21.

9. Jayne D, Pigazzi A, Marshall H, Croft J, Corrigan N, Copeland J, et al. Effect of robotic-assisted vs conventional laparoscopic surgery on risk of conversion to open laparotomy among patients undergoing resection for rectal cancer: the ROLARR randomized clinical trial. JAMA 2017:318:1569-80.

10. Baik SH, Ko YT, Kang CM, Lee WJ, Kim NK, Sohn SK, et al. Robotic tumor-specific mesorectal excision of rectal cancer: short-term outcome of a pilot randomized trial. Surg Endosc 2008:22:1601-8.

11. Melich G, Hong YK, Kim J, Hur H, Baik SH, Kim NK, et al. Simultaneous development of laparoscopy and robotics provides acceptable perioperative outcomes and shows robotics to have a faster learning curve and to be overall faster in rectal cancer surgery: analysis of novice MIS surgeon learning curves. Surg Endosc 2015; 29:558-68.

12. Choi DJ, Kim SH, Lee PJ, Kim J, Woo SU. Single-stage totally robotic dissection for rectal cancer surgery: technique and short-term outcome in 50 consecutive patients. Dis Colon Rectum 2009:52:182430.

13. Ngu JC, Sim S, Yusof S, Ng CY, Wong AS. Insight into the da Vinci® Xi - technical notes for single-docking left-sided colorectal procedures. Int J Med Robot 2017;13:e1798.

14. DeNoto G, Rubach E, Ravikumar TS. A standardized technique for robotically performed sigmoid colectomy. J Laparoendosc Adv Surg Tech A 2006;16:551-6.

15. Bokhari MB, Patel CB, Ramos-Valadez DI, Ragupathi M, Haas EM. Learning curve for robotic-assisted laparoscopic colorectal surgery. Surg Endosc 2011;25:855-60.

16. Jimenez-Rodriguez RM, Diaz-Pavon JM, de la Portilla de Juan F, Prendes-Sillero E, Dussort HC, Padillo J. Learning curve for robotic-assisted laparoscopic rectal cancer surgery. Int J Colorectal Dis 2013;28:815-
21.

17. Parra-Davila E, Diaz-Hernandez JJ. Totally robotic left colectomy. J Robot Surg 2011;5: 57-64.

18. Protyniak B, Jorden J, Farmer R. Multiquadrant robotic colorectal surgery: the da Vinci Xi vs Si comparison. J Robot Surg 2018;12:67-74.

19. Morelli L, Guadagni S, Di Franco G, Palmeri M, Caprili G, D'Isidoro C, et al. Use of the new da Vinci Xi® during robotic rectal resection for cancer: a pilot matched-case comparison with the da Vinci Siß. Int J Med Robot 2017 Mar;13(1) [Epub]. https://doi.org/10.1002/rcs.1728.

20. Leal Ghezzi T, Campos Corleta O. 30 Years of robotic surgery. World J Surg 2016:40:2550-7.

21. Lee HJ, Choi GS, Park JS, Park SY, Kim HJ, Woo IT, et al. A novel robotic right colectomy for colon cancer via the suprapubic approach using the da Vinci Xi system: initial clinical experience. Ann Surg Treat Res 2018;94:83-7.

22. Reitz ACW, Lin E, Rosen SA. A single surgeon's experience transitioning to robotic-assisted right colectomy with intracorporeal anastomosis. Surg Endosc 2018;32:3525-32.

23. Trastulli S, Desiderio J, Farinacci F, Ricci F, Listorti C, Cirocchi R, et al. Robotic right colectomy for cancer with intracorporeal anastomosis: short-term outcomes from a single institution. Int J Colorectal Dis 2013;28:807-14.

24. Park SY, Choi GS, Park JS, Kim HJ, Choi WH, Ryuk JP. Robot-assisted right colectomy with lymphadenectomy and intracorporeal anastomosis for colon cancer: technical considerations. Surg Laparosc Endosc Percutan Tech 2012;22:e2716.

25. Chouillard E, Chahine E, Khoury G, Vinson-Bonnet B, Gumbs A, Azoulay D, et al. NOTES total mesorectal excision (TME) for patients with rectal neoplasia: a preliminary experience. Surg Endosc 2014:28:3150-7.

26. Atallah S, Martin-Perez B, Albert M, deBeche-Adams T, Nassif G, Hunter L, et al. Transanal minimally invasive surgery for total mesorectal excision (TAMISTME): results and experience with the first 20 patients undergoing curativeintent rectal cancer surgery at a single institution. Tech Coloproctol 2014;18:47380.

27. Verheijen PM, Consten EC, Broeders IA. Robotic transanal total mesorectal excision for rectal cancer: experience with a first case. Int J Med Robot 2014;10:423-6.

28. Gomez Ruiz M, Parra IM, Palazuelos CM, Martin JA, Fernandez CC, Diego JC, et al. Robotic-assisted laparoscopic transanal total mesorectal excision for rectal cancer: a prospective pilot study. Dis Colon Rectum 2015;58:145-53.

29. Kuo LJ, Ngu JC, Tong YS, Chen CC. Combined robotic transanal total mesorectal excision (R-taTME) and singlesite plus one-port (R-SSPO) technique for ultra-low rectal surgery-initial experience with a new operation approach. Int J Colorectal Dis 2017:32:249-54.

30. Kim JC. A universal port design for the da Vinci $\mathrm{Xi}{ }^{\circledR}$ system allowing access to the entire colon for colorectal cancer surgery. J Surg Oncol 2016;114:1029-30.

31. Ng KH, Lim YK, Ho KS, Ooi BS, Eu KW. Robotic-assisted surgery for low rectal dissection: from better views to better outcome. Singapore Med J 2009:50:763-7.

32. Prasad LM, deSouza AL, Marecik SJ, Park JJ, Abcarian H. Robotic pursestring technique in low anterior resection. Dis Colon Rectum 2010;53:230-4.

33. Zimmern A, Prasad L, Desouza A, Marecik S, Park J, Abcarian H. Robotic colon and rectal surgery: a series of 131 cases. World J Surg 2010;34:1954-8.

34. Patel CB, Ragupathi M, Ramos-Valadez DI, Haas EM. A three-arm (laparoscopic, hand-assisted, and robotic) matchedcase analysis of intraoperative and postoperative outcomes in minimally invasive colorectal surgery. Dis Colon Rectum 2011:54:144-50.

35. Deutsch GB, Sathyanarayana SA, Gunabushanam V, Mishra N, Rubach E, Zemon $\mathrm{H}$, et al. Robotic vs. laparoscopic colorectal surgery: an institutional experience. Surg Endosc 2012;26:956-63. 
36. Park JS, Choi GS, Lim KH, Jang YS, Jun SH. S052: a comparison of robot-assisted, laparoscopic, and open surgery in the treatment of rectal cancer. Surg Endosc 2011;25:240-8.

37. Ragupathi M, Ramos-Valadez DI, Patel CB, Haas EM. Robotic-assisted laparoscopic surgery for recurrent diverticulitis: experience in consecutive cases and a review of the literature. Surg Endosc 2011; 25:199-206.

38. Koh DC, Tsang CB, Kim SH. A new application of the four-arm standard da Vinci® surgical system: totally robotic-assisted left-sided colon or rectal resection. Surg Endosc 2011;25:1945-52.

39. Kim JY, Kim NK, Lee KY, Hur H, Min BS, Kim JH. A comparative study of voiding and sexual function after total mesorectal excision with autonomic nerve preservation for rectal cancer: laparoscopic versus robotic surgery. Ann Surg Oncol 2012;19:2485-93.

40. Shin JY. Comparison of short-term surgical outcomes between a robotic colectomy and a laparoscopic colectomy during early experience. J Korean Soc Coloproctol 2012;28:19-26.

41. Park JA, Choi GS, Park JS, Park SY. Initial clinical experience with robotic lateral pelvic lymph node dissection for advanced rectal cancer. J Korean Soc Coloproctol 2012;28:265-70.

42. Zawadzki M, Velchuru VR, Albalawi SA, Park JJ, Marecik S, Prasad LM. Is hybrid robotic laparoscopic assistance the ideal approach for restorative rectal cancer dissection? Colorectal Dis 2013;15:102632.

43. Kenawadekar RD, Dhange RZ, Pandit A, Bandawar MS, Joshi S, Agarwal G, et al. Robot-assisted low anterior resection in fifty-three consecutive patients: an Indian experience. J Robot Surg 2013;7:311-6.

44. Parisi A, Desiderio J, Trastulli S, Cirocchi R, Ricci F, Farinacci F, et al. Robotic rectal resection for cancer: a prospective cohort study to analyze surgical, clinical and oncological outcomes. Int J Surg 2014;12:1456-61.

45. Kim HJ, Choi GS, Park JS, Park SY.
Multidimensional analysis of the learning curve for robotic total mesorectal excision for rectal cancer: lessons from a single surgeon's experience. Dis Colon Rectum 2014:57:1066-74.

46. Liang JT, Lai HS. Surgical technique of robotic D3 lymph node dissection around the inferior mesenteric artery with preservation of the left colic artery and autonomic nerves for the treatment of distal rectal cancer. Surg Endosc 2014;28:1727-33.

47. Kuo LJ, Lin YK, Chang CC, Tai CJ, Chiou JF, Chang YJ. Clinical outcomes of robotassisted intersphincteric resection for low rectal cancer: comparison with conventional laparoscopy and multifactorial analysis of the learning curve for robotic surgery. Int J Colorectal Dis 2014:29:555-62.

48. Sawada H, Egi H, Hattori M, Suzuki T, Shimomura M, Tanabe $\mathrm{K}$, et al. Initial experiences of robotic versus conventional laparoscopic surgery for colorectal cancer, focusing on short-term outcomes: a matched case-control study. World J Surg Oncol 2015;13:103.

49. Gorgun E, Aytac E, Gurland B, Costedio MM. Case-matched comparison of robotic versus laparoscopic colorectal surgery: initial institutional experience. Surg Laparosc Endosc Percutan Tech 2015;25:e148-51.

50. Bae SU, Min BS, Kim NK. Robotic low ligation of the inferior mesenteric artery for rectal cancer using the firefly technique. Yonsei Med J 2015;56:1028-35.

51. Huang CW, Yeh YS, Ma CJ, Choy TK, Huang MY, Huang CM, et al. Robotic colorectal surgery for laparoscopic surgeons with limited experience: preliminary experiences for 40 consecutive cases at a single medical center. BMC Surg 2015;15:73.

52. Pai A, Marecik SJ, Park JJ, Melich G, Sulo S, Prasad LM. Oncologic and clinicopathologic outcomes of robot-assisted total mesorectal excision for rectal cancer. Dis Colon Rectum 2015:58:659-67.

53. Eftaiha SM, Pai A, Sulo S, Park JJ, Prasad LM, Marecik SJ. Robot-assisted abdominoperineal resection: clinical, pathologic, and oncologic outcomes. Dis Colon Rectum 2016:59:607-14.

54. Kim YS, Kim MJ, Park SC, Sohn DK, Kim DY, Chang HJ, et al. Robotic versus laparoscopic surgery for rectal cancer after preoperative chemoradiotherapy: casematched study of short-term outcomes. Cancer Res Treat 2016;48:225-31.

55. Zaghloul AS, Mahmoud AM. Preliminary results of robotic colorectal surgery at the National Cancer Institute, Cairo University. J Egypt Natl Canc Inst 2016;28:169-74.

56. Rencuzogullari A, Gorgun E, Costedio M, Aytac E, Kessler H, Abbas MA, et al. Casematched comparison of robotic versus laparoscopic proctectomy for inflammatory bowel disease. Surg Laparosc Endosc Percutan Tech 2016;26:e37-40.

57. Luca F, Valvo M, Guerra-Cogorno M, Simo D, Blesa-Sierra E, Biffi R, et al. Functional results of robotic total intersphincteric resection with hand-sewn coloanal anastomosis. Eur J Surg Oncol 2016;42:841-7.

58. Gorgun E, Ozben V, Costedio M, Stocchi L, Kalady M, Remzi F. Robotic versus conventional laparoscopic rectal cancer surgery in obese patients. Colorectal Dis 2016;18:1063-71.

59. Gomez Ruiz M, Alonso Martin J, Cagigas Fernandez C, Martin Parra JI, Real Noval H, Martin Rivas B, et al. Short- and midterm outcomes of robotic-assisted total mesorectal excision for the treatment of rectal cancer. Our experience after 198 consecutive cases. Eur J Surg Oncol 2016;42:848-54.

60. Kim CN, Bae SU, Lee SG, Yang SH, Hyun IG, Jang JH, et al. Clinical and oncologic outcomes of totally robotic total mesorectal excision for rectal cancer: initial results in a center for minimally invasive surgery. Int J Colorectal Dis 2016:31:843-52.

61. Ahmed J, Siddiqi N, Khan L, Kuzu A, Parvaiz A. Standardized technique for single-docking robotic rectal surgery. Colorectal Dis 2016;18:0380-4.

62. Huang YM, Huang YJ, Wei PL. Outcomes of robotic versus laparoscopic surgery for mid and low rectal cancer after 
neoadjuvant chemoradiation therapy and the effect of learning curve. Medicine (Baltimore) 2017;96:e8171.

63. Oldani A, Bellora P, Monni M, Amato B, Gentilli S. Colorectal surgery in elderly patients: our experience with DaVinci $\mathrm{Xi}{ }^{\circledR}$ System. Aging Clin Exp Res 2017;29(Suppl 1):91-9.

64. Pesi B, Annecchiarico M, Amore Bonapasta S, Nerini A, Perna F, Bencini L, et al. Robotic rectal resection with a singledocking technique thanks to the rotation of the R3 arm. Surg Laparosc Endosc Percutan Tech 2017;27:e18-21.

65. Huang CW, Tsai HL, Yeh YS, Su WC, Huang MY, Huang CM, et al. Roboticassisted total mesorectal excision with the single-docking technique for patients with rectal cancer. BMC Surg 2017;17:126.

66. Kuo LJ, Ngu JC, Huang YJ, Lin YK, Chen CC, Tong YS, et al. Anorectal complications after robotic intersphincteric resection for low rectal cancer. Surg Endosc 2017;31: 4466-71.

67. Panteleimonitis S, Harper M, Hall S, Figueiredo N, Qureshi T, Parvaiz A. Precision in robotic rectal surgery using the da Vinci Xi system and integrated table motion, a technical note. J Robot Surg 2018;12:433-6.

68. Nolan HR, Smith BE, Honaker MD. Operative time and length of stay is similar between robotic assisted and laparoscopic colon and rectal resections. J Robot Surg 2018;12:659-64.

69. Aselmann H, Kersebaum JN, Bernsmeier A, Beckmann JH, Moller T, Egberts JH, et al. Robotic-assisted total mesorectal excision (TME) for rectal cancer results in a significantly higher quality of TME specimen compared to the laparoscopic approach-report of a single-center experience. Int J Colorectal Dis 2018;33: 1575-81.

70. Debakey Y, Zaghloul A, Farag A, Mahmoud A, Elattar I. Robotic-assisted versus conventional laparoscopic approach for rectal cancer surgery, first egyptian academic center experience, RCT. Minim Invasive Surg 2018;2018:5836562.

71. Cassini D, Depalma N, Grieco M, Cirocchi
R, Manoochehri F, Baldazzi G. Robotic pelvic dissection as surgical treatment of complicated diverticulitis in elective settings: a comparative study with fully laparoscopic procedure. Surg Endosc 2019; 33:2583-90.

72. Ishihara S, Kiyomatsu T, Kawai K, Tanaka T, Hata K, Kazama S, et al. The short-term outcomes of robotic sphincter-preserving surgery for rectal cancer: comparison with open and laparoscopic surgery using a propensity score analysis. Int J Colorectal Dis 2018;33:1047-55.

73. Luca F, Cenciarelli S, Valvo M, Pozzi S, Faso FL, Ravizza D, et al. Full robotic left colon and rectal cancer resection: technique and early outcome. Ann Surg Oncol 2009;16:1274-8.

74. Bae SU, Baek SJ, Hur H, Baik SH, Kim NK, Min BS. Robotic left colon cancer resection: a dual docking technique that maximizes splenic flexure mobilization. Surg Endosc 2015;29:1303-9.

75. Maciel V, Lujan HJ, Plasencia G, Zeichen M, Mata W, Jorge I, et al. Diverticular disease complicated with colovesical fistula: laparoscopic versus robotic management. Int Surg 2014:99:203-10.

76. Kim JC, Lee JL, Yoon YS, Kim CW, Park IJ, Lim SB. Robotic left colectomy with complete mesocolectomy for splenic flexure and descending colon cancer, compared with a laparoscopic procedure. Int J Med Robot 2018;14:e1918.

77. deSouza AL, Prasad LM, Park JJ, Marecik SJ, Blumetti J, Abcarian H. Robotic assistance in right hemicolectomy: is there a role? Dis Colon Rectum 2010;53:1000-6.

78. D'Annibale A, Pernazza G, Morpurgo E, Monsellato I, Pende V, Lucandri G, et al. Robotic right colon resection: evaluation of first 50 consecutive cases for malignant disease. Ann Surg Oncol 2010;17:2856-62.

79. Huettner F, Pacheco PE, Doubet JL, Ryan MJ, Dynda DI, Crawford DL. One hundred and two consecutive robotic-assisted minimally invasive colectomies--an outcome and technical update. J Gastrointest Surg 2011;15:1195-204.

80. Luca F, Ghezzi TL, Valvo M, Cenciarelli S, Pozzi S, Radice D, et al. Surgical and pathological outcomes after right hemicolectomy: case-matched study comparing robotic and open surgery. Int J Med Robot 2011;7:298-303.

81. Park JS, Choi GS, Park SY, Kim HJ, Ryuk JP. Randomized clinical trial of robotassisted versus standard laparoscopic right colectomy. Br J Surg 2012;99:1219-26.

82. Lujan HJ, Maciel VH, Romero R, Plasencia G. Laparoscopic versus robotic right colectomy: a single surgeon's experience. J Robot Surg 2013;7:95-102.

83. Zawadzki M, Rzaca M, Czarnecki R, Obuszko Z, Jacyna K, Stewart L, et al. Beginning robotic assisted colorectal surgery - it's harder than it looks! Wideochir Inne Tech Maloinwazyjne 2014:9:5628.

84. Megevand JL, Amboldi M, Lillo E, Lenisa L, Ganio E, Ambrosi A, et al. Right colectomy: consecutive 100 patients treated with laparoscopic and robotic technique for malignancy. Cumulative experience in a single centre. Updates Surg 2019;71:1516.

85. Buchs NC, Pugin F, Ris F, Volonte F, Morel P, Roche B. Early experience with robotic rectopexy. Int J Med Robot 2013;9:e61-5.

86. Mantoo S, Podevin J, Regenet N, Rigaud J, Lehur PA, Meurette G. Is roboticassisted ventral mesh rectopexy superior to laparoscopic ventral mesh rectopexy in the management of obstructed defaecation? Colorectal Dis 2013;15:e469-75.

87. Mehmood RK, Parker J, Bhuvimanian L, Qasem E, Mohammed AA, Zeeshan M, et al. Short-term outcome of laparoscopic versus robotic ventral mesh rectopexy for full-thickness rectal prolapse. Is robotic superior? Int J Colorectal Dis 2014:29:11138.

88. Inaba CS, Sujatha-Bhaskar S, Koh CY, Jafari MD, Mills SD, Carmichael JC, et al. Robotic ventral mesh rectopexy for rectal prolapse: a single-institution experience. Tech Coloproctol 2017;21:667-71.

89. Hompes R, Rauh SM, Ris F, Tuynman JB, Mortensen NJ. Robotic transanal minimally invasive surgery for local excision of rectal neoplasms. Br J Surg 2014;101:578-81. 
90. Ngu JC, Kuo LJ, Kung CH, Chen CL, Kuo CC, Chang SW, et al. Robotic transanal minimally invasive surgery for rectal cancer after clinical complete response to neoadjuvant chemoradiation. Int J Med Robot 2018;14:e1948.
91. Arnott S, Skancke M, Obias V. Robotic transanal microsurgery for high early rectal neoplasia (T0-T1, N0 lesions), case series of 10 patients. Int J Med Robot 2018;14:e1956.

92. Tomassi MJ, Taller J, Yuhan R, Ruan
JH, Klaristenfeld DD. Robotic transanal minimally invasive surgery for the excision of rectal neoplasia: clinical experience with 58 consecutive patients. Dis Colon Rectum 2019;62:279-85. 